\title{
Redução do nível de proteína bruta da ração com suplementação de aminoácidos sintéticos para leitões na fase inicial ${ }^{1}$
}

\section{Márcio Gilberto Zangeronimo², Elias Tadeu Fialho ${ }^{3}$, José Augusto de Freitas Lima ${ }^{3}$, Paulo Borges Rodrigues ${ }^{3}$, Luis David Solis Murgas ${ }^{4}$}

\author{
${ }^{1}$ Parte da tese de Mestrado apresentada à Universidade Federal de Lavras pelo primeiro autor. Financiado pelo CNPq. \\ 2 Doutor em Nutrição de Monogástricos - DZO - UFLA. \\ ${ }^{3}$ Departamento de Zootecnia - UFLA. Bolsista do CNPq. \\ ${ }^{4}$ Departamento de Medicina Veterinária - UFLA. Bolsista do CNPq.
}

RESUMO - Avaliou-se o efeito da redução do nível de PB e do farelo de soja, com suplementação de aminoácidos, na ração sobre o desempenho, a excreção de $\mathrm{N}$, o peso dos órgãos e a incidência de diarréia em leitões na fase inicial. As dietas continham quatro níveis de $\mathrm{PB}(21,0 ; 19,5 ; 18,0$ e $16,5 \%)$ e foram suplementadas com os aminoácidos lisina, metionina e treonina. No experimento I, oito suínos machos castrados $(\mathrm{PV}=22,0 \mathrm{~kg}$ ), mestiços $(\mathrm{LD} \times \mathrm{LW}$ ), foram alojados individualmente em um delineamento em blocos casualizados com parcela subdividida no tempo, para determinação do balanço de N. O consumo de N e a excreção nas fezes não foram afetados pelos tratamentos, porém, houve decréscimo linear da excreção na urina com a redução da PB dietética. No experimento II, 60 animais ( $\mathrm{PV}=8,5 \mathrm{~kg}$ ) foram alojados em delineamento de blocos casualizados, em esquema fatorial 4 x 3 (quatro dietas e três épocas de abate), com cinco blocos e um animal por unidade experimental, para avaliação do peso relativo do fígado, baço e pâncreas e da morfometria intestinal nas três primeiras semanas pós-desmame. Não houve diferenças significativas entre os tratamentos, exceto para a profundidade de criptas na primeira semana, que apresentou efeito cúbico. No experimento III, 60 animais ( $\mathrm{PV}=8,0 \mathrm{~kg}$ ) foram alojados em delineamento de blocos casualizados, com cinco blocos e três animais por unidade experimental, para estudo do desempenho e da incidência de diarréia. Não houve diferenças significativas para os parâmetros avaliados, porém observou-se redução na incidência de diarréia nos animais que receberam rações contendo $16,5 \%$ de PB. A redução do nível de PB de 21 para 16,5\% na dieta de leitões na fase inicial é viável para redução da excreção de $\mathrm{N}$ na urina e da incidência de diarréia, pois não afeta os parâmetros físiológicos e de desempenho de leitões dos 10 aos $25 \mathrm{~kg}$ PV.

Palavras-chave: desempenho, farelo de soja, metabolismo, nutrição, proteína ideal, suínos

\section{Effects of reducing dietary crude protein levels for piglets supplemented with synthetic amino acid}

\begin{abstract}
The effects of reducing dietary CP and soybean meal levels on performance, $\mathrm{N}$ excretion, organs weight and diarrhea incident were evaluated in pigs supplemented with amino acids. The diets contained four levels of CP (21.0, 19.5, 18.0, and 16.5\%) and were supplemented with synthetic amino acid (lysine, metionine and treonine). In experiment I, eight crossbred (LD x LW) castrated males (initial weight $=22 \mathrm{~kg}$ ) were individually allotted to a randomized block design, with split plot arrangement to determine $\mathrm{N}$ balance. No significant changes in amount of $\mathrm{N}$ ingested and excreted in the feces were observed among the treatments. However, the treatments linearly decreased $\mathrm{N}$ excreted in the urine, as dietary CP decreased. In experiment II, 60 pigs (initial weight $=8.5 \mathrm{~kg}$ ) were assigned to a randomized blocks design with $4 \times 3$ factorial arrangement (four diets and three slaughter ages), with five blocks and one animal per unit experimental, to evaluate the relative weights of liver, spleen and pancreas and intestinal morfometry during the first three post weaning weeks. No significant differences on these parameters were observed across the treatments, whereas crypt depth changed in the first post weaning week, that showed cubic effect. In experiment III, 60 animals (initial weight $=8,0 \mathrm{~kg}$ ) were allotted to a randomized blocks design, with five blocks and three animals per experimental unit, to evaluate the performance and diarrhea incidence. No significant differences on these parameters were observed across the treatments. Pigs fed diet with $16.5 \% \mathrm{CP}$ showed decreasing diarrhea incidence. Reducing the dietary CP levels from 21 to $16.5 \%$ for pigs in the nursery phase decreased $\mathrm{N}$ excretion in the urine and diarrhea incidence with no changes on performance and physiologic parameters of piglets from 8 to $25 \mathrm{~kg} \mathrm{BW}$.
\end{abstract}

Key Words: ideal protein, metabolism, nutrition, performance growth, soybean meal, swine

\section{Introdução}

Na formulação de rações para suínos, tem-se como objetivo suprir os requerimentos nutricionais, adequando as quantidades de nutrientes ingeridos e absorvidos de acordo com o nível de produção desejado.

Durante muitos anos, as rações foram formuladas com base no conceito de proteína bruta, resultando 
em dietas com conteúdo de aminoácidos acima do exigido pelos animais. A aplicação do conceito da proteína ideal tem permitido aos nutricionistas formular rações mais adequadas às exigências nutricionais de cada categoria animal, melhorando a eficiência de utilização dos nutrientes contidos nos alimentos e reduzindo a excreção de resíduos ao meio ambiente, principalmente os nitrogenados.

De acordo com de De la Llata et al. (2002), a redução do nível de proteína bruta e a suplementação de aminoácidos sintéticos, mantendo-se a relação aminoacídica de uma dieta (proteína ideal), podem reduzir a emissão de nitrogênio nos dejetos sem prejudicar o desempenho dos animais.

Quanto ao tipo de dieta ideal para leitões na fase inicial, existem ainda muitas controvérsias na literatura atual. O nível de inclusão de farelo de soja na ração tem sido discutido, uma vez que este ingrediente possui fatores alergênicos e fatores antinutricionais responsáveis pela queda nos índices de desempenho dos leitões desmamados precocemente.

Além da baixa atividade das enzimas pancreáticas e intestinais, o reduzido aproveitamento da proteína de origem vegetal pelos leitões em relação a um animal adulto ocorre em razão da menor produção de ácido no estômago. Conseqüentemente, o excesso de proteína não digerida favorece a proliferação de microrganismos patogênicos no trato digestivo e no ambiente, via dejetos, aumentando a incidência de diarréias e interferindo no aspecto sanitário da produção (Suida, 2001). Além disso, antígenos dietéticos presentes em alguns alimentos de origem vegetal podem desenvolver uma resposta imune no intestino, resultando em encurtamento das vilosidades e hiperplasia das criptas.

Diante do exposto, obejtivou-se com este estudo avaliar os efeitos da redução do nível de PB na dieta, via suplementação de aminoácidos, sobre a excreção de nitrogênio nos dejetos e o efeito da redução na participação do farelo de soja sobre o desempenho, o peso de órgãos e a incidência de diarréia em leitões na fase inicial.

\section{Material e Métodos}

Os experimentos foram conduzidos no Setor de Suinocultura do Departamento de Zootecnia da Universidade Federal de Lavras (UFLA), em Lavras, região sul do estado de Minas Gerais.

As dietas foram formuladas para conter níveis decrescentes de $\mathrm{PB}(21,0 ; 19,5 ; 18,0$ e 16,5\%), por meio da redução do nível de farelo de soja e pela suplementação de aminoácidos sintéticos (lisina, metionina e treonina),
Tabela 1 - Composição percentual das rações experimentais Table 1 Ingredient composition of the experimental diets

\begin{tabular}{|c|c|c|c|c|}
\hline \multirow[t]{2}{*}{$\begin{array}{l}\text { Ingrediente } \\
\text { Ingredient }\end{array}$} & \multicolumn{4}{|c|}{$\begin{array}{c}\text { Nível de proteína bruta } \\
\text { na ração (\%) } \\
\text { Protein level in diet }\end{array}$} \\
\hline & 21,0 & 19,5 & 18,0 & 16,5 \\
\hline Sorgo BT & 52,35 & 53,68 & 53,44 & 53,42 \\
\hline Sorghum LT & & & & \\
\hline Farelo de soja & 32,0 & 28,5 & 25,3 & 22,0 \\
\hline $\begin{array}{l}\text { Soybean meal } \\
\text { Óleo de soja }\end{array}$ & 1,9 & 1,9 & 1,9 & 1,9 \\
\hline $\begin{array}{l}\text { Soybean oil } \\
\text { Leite em pó modificado } \\
\text { Dried milk }\end{array}$ & 5,0 & 5,0 & 5,0 & 5,0 \\
\hline $\begin{array}{l}\text { Amido de mandioca } \\
\text { Cassava starch }\end{array}$ & 6,0 & 8,0 & 11,2 & 14,3 \\
\hline $\begin{array}{l}\text { Fosfato bicálcico } \\
\text { Dicalcium phosphate }\end{array}$ & 1,25 & 1,31 & 1,42 & 1,53 \\
\hline $\begin{array}{l}\text { Calcário calcítico } \\
\text { Limestone }\end{array}$ & 0,94 & 0,94 & 0,9 & 0,85 \\
\hline $\begin{array}{l}\text { Sal iodado } \\
\text { Salt }\end{array}$ & 0,3 & 0,3 & 0,3 & 0,3 \\
\hline Premix vitamínico ${ }^{1}$ & 0,1 & 0,1 & 0,1 & 0,1 \\
\hline $\begin{array}{l}\text { Premix vitamin } \\
\text { Premix mineral }{ }^{2}\end{array}$ & 0,1 & 0,1 & 0,1 & 0,1 \\
\hline $\begin{array}{l}\text { Premix mineral } \\
\text { L-lisina } \mathrm{HCl} 78 \%\end{array}$ & 0,01 & 0,11 & 0,21 & 0,31 \\
\hline $\begin{array}{l}\text { L-lysine } \mathrm{HCl} 78 \% \\
\text { DL-metionina } 98 \%\end{array}$ & 0,01 & 0,03 & 0,05 & 0,07 \\
\hline DL-methionine $98 \%$ & & & & \\
\hline L-treonina & 0 & 0 & 0,04 & 0,09 \\
\hline $\begin{array}{l}\text { L-threonine } \\
\text { Bacitracina de zinco }\end{array}$ & 0,03 & 0,03 & 0,03 & 0,03 \\
\hline
\end{tabular}

Valores calculados

Calculated values

Proteína bruta (\%)

$21,0 \quad 19,5 \quad 18,0 \quad 16,5$

Crude protein

$\begin{array}{lllll}\text { Energia digestível }(\mathrm{kcal} / \mathrm{kg}) & 3.400 & 3.400 & 3.400 & 3.400\end{array}$

Digestible energy

$\mathrm{Ca}(\%)$

Fósforo disponível (\%)

Available phosphorus

Lisina digestível (\%)

Digestible lysine

Metionina digestível (\%)

Digestible methionine

Treonina digestível (\%)

Digestible threonine

$\begin{array}{llll}0,83 & 0,83 & 0,83 & 0,83\end{array}$

$0,41 \quad 0,41 \quad 0,41 \quad 0,41$

$0,93 \quad 0,93 \quad 0,93 \quad 0,93$

$0,28 \quad 0,28 \quad 0,28 \quad 0,28$

$\begin{array}{llll}0,66 & 0,61 & 0,60 & 0,60\end{array}$

1 Suplemento vitamínico contendo: vitamina $A, 8.000 .000$ UI; vitamina $D_{3}$ $1.200 .000 \mathrm{UI}$; vitamina $\mathrm{E}, 20 \mathrm{~g}$; vitamina $\mathrm{K}_{3}, 2.500 \mathrm{mg}$; vitamina $\mathrm{B}_{1}$ $1.000 \mathrm{mg}$; riboflavina $\left(B_{2}\right), 4.000 \mathrm{mg}$; piridoxina $\left(B_{6}\right), 2.000 \mathrm{mg}$; vitamina $\mathrm{B}_{12}, 20.000 \mathrm{mcg}$; niacina, $25.000 \mathrm{mg}$; ácido pantotênico, $10 \mathrm{~g}$; ácido fólico, $600 \mathrm{mg}$; biotina, $50 \mathrm{mg}$; vitamina C, $50 \mathrm{~g}$; antioxidante, $125 \mathrm{mg}$ e excipiente q.s.q. $1000 \mathrm{~g}$.

2 Suplemento mineral contendo, por kg do produto: selênio, $500 \mathrm{mg}$; ferro, $180 \mathrm{~g}$; cobre, $20 \mathrm{~g}$; manganês, $80 \mathrm{~g}$; zinco, $140 \mathrm{~g}$; iodo, $4 \mathrm{~g}$; cobalto,

$4 \mathrm{~g}$ e excipiente q.s.q. $1000 \mathrm{~g}$

${ }^{1}$ Vitamin supplemented with:vitamin $A, 8.000 .000 \mathrm{Ul}$; vitamin $D_{3}, 1.200 .000 \mathrm{Ul}$; vitamin $\mathrm{E}, 20 \mathrm{~g}$; vitamin $K_{3}, 2.500 \mathrm{mg}$ : vitamin $B_{1}, 1.000 \mathrm{mg}$ : riboflavin ( $\left.B_{2}\right), 4.000 \mathrm{mg}$ : piridoxin ( $\left.B_{6}\right), 2.000 \mathrm{mg}$ : vitamin $B_{12}, 20 \mathrm{mg}$; niacin, $25 \mathrm{mg}$; panthotenic acid, $10 \mathrm{~g}$; folic acid, $600 \mathrm{mg}$; biotin, $50 \mathrm{mg}$ vitamin C, 50 g; antioxidant, $125 \mathrm{mg}$ and excipient q.s.q. $1000 \mathrm{~g}$.

${ }^{2}$ Mineralsupplement with: selenium, $500 \mathrm{mg}$; iron, $180 \mathrm{~g}$; copper, $20 \mathrm{~g}$ : manganese, $80 \mathrm{~g}$ zinc, $140 \mathrm{mg}$; iodine, $4 \mathrm{~g}$; cobalt, $4 \mathrm{~g}$ and excipient q.s.q. $1000 \mathrm{~g}$. 
segundo o conceito de proteína ideal, atendendo às recomendações de Rostagno et al. (2000). A composição percentual das rações experimentais encontra-se na Tabela 1.

No experimento I, foram utilizados oito suínos machos castrados (LD x LW), com peso inicial de $22,0 \pm 2,4 \mathrm{~kg}$, mantidos em gaiolas de estudos de metabolismo semelhantes às descritas por Sales et al. (2003). As gaiolas foram mantidas em salas equipadas com ar condicionado, permitindo o controle da temperatura interna da sala em $22,0 \pm 2,0^{\circ} \mathrm{C}$.

$\mathrm{O}$ experimento foi dividido em três períodos de nove dias, sendo cinco destinados à adaptação dos animais às gaiolas, às rações experimentais e ao ajuste do consumo voluntário e quatro, à coleta de fezes e urina. O óxido férrico $\left(\mathrm{Fe}_{2} \mathrm{O}_{3}\right)$ foi utilizado como marcador fecal e as quantidades de ração foram alculadas com base no peso metabólico de cada animal, ajustadas à do animal de menor consumo. A coleta do material foi realizada conforme metodologia descrita por Fialho et al. (1979). Analisaram-se os teores de matéria seca (com exceção da urina) e $\mathrm{N}$ de todo o material coletado e das rações experimentais, segundo metodologia proposta por Silva (1990), para determinação dos teores de $\mathrm{N}$ absorvido e retido pelo animal, bem como de $\mathrm{N}$ ingerido e $\mathrm{N}$ excretado nas fezes e na urina. As análises foram realizadas no Laboratório de Pesquisa Animal da Universidade Federal de Lavras.

No experimento II, foram utilizados 60 animais, machos castrados e fêmeas (LD x LW) com pesos inicial e final de 8,55 $\pm 0,81$ e $25,1 \pm 3,75 \mathrm{~kg}$, respectivamnte, alojados em sala de alvenaria (no galpão de creche), em grupos de três, em baias suspensas $(2,00 \times 1,20 \mathrm{~m})$ a 1,20 m de altura, com piso ripado, dotadas de comedouros semi-automáticos e bebedouro tipo chupeta, durante 21 dias. $\mathrm{O}$ ambiente foi semicontrolado com lâmpadas para aquecimento e ventiladores.

Semanalmente, cinco animais de cada tratamento foram abatidos (um de cada baia, escolhendo-se aquele com peso mais próximo à média da parcela) até o 210 dia após o início do experimento (amostras semanais). Após cada abate, procedeu-se à abertura na cavidade abdominal por incisão ventral, seguida de evisceração. De cada animal foram coletadas amostras da parede do duodeno (aproximadamente $2 \mathrm{~cm}$ de comprimento do terço médio do duodeno) e pesados o baço, o fígado e o pâncreas. As amostras do intestino foram imediatamente lavadas em água destilada, identificadas e fixadas em Boin (solução aquosa saturada de ácido pícrico, formol e ácido acético) por 24 horas. Em seguida, o material foi lavado e conservado em álcool $70 \%$ para análises subseqüentes. A preparação das lâminas foi realizada no Laboratório de Patologia do Departamento de Medicina Veterinária da UFLA, utilizando-se a técnica descrita por Junqueira \& Junqueira (1983), com algumas adaptações.
Para análise das variáveis deste experimento, foi adotado um delineamento em blocos casualizados, em esquema fatorial $4 \times 3$ (quatro dietas e três épocas de abate), com cinco repetições, sendo os blocos constituídos pela idade dos animais. A unidade experimental, representada por um animal, foi distribuída aleatoriamente ao longo da sala, com base na idade dos animais e nos tratamentos aplicados.

No experimento III, foram utilizados 60 animais $(8,0 \pm$ $0,74 \mathrm{~kg} \mathrm{PV}$ ) alojados e mantidos nas mesmas condições do experimento II. O período experimental teve duração de 42 dias, quando foi feito o monitoramento diário da incidência de diarréia, segundo a escala: $0=$ fezes normais; $1=$ fezes moles; 2 = fezes pastosas; 3 = fezes aquosas. As avaliações foram realizadas diariamente pela manhã, por dois avaliadores, associando cada baia a esta escala. A temperatura interna da sala foi mantida entre 18,7 e $24,9^{\circ} \mathrm{C}$ e as rações e a água foram fornecidas à vontade.

Os animais foram pesados no início e ao final do experimento, quando foram pesadas também as rações e as sobras. A conversão alimentar foi obtida pela relação entre o consumo de ração e o ganho de peso durante o período experimental.

Adotou-se, neste experimento, o delineamento de blocos casualizados, com quatro tratamentos e cinco repetições, em que os blocos consistiram nas épocas de desmame. A unidade experimental foi representada por três animais, distribuídos pela sala, com base na época de desmame e nos tratamentos aplicados.

Em todos os experimentos, as análises estatísticas foram realizadas pelo pacote estatístico SISVAR, descrito por Ferreira (2000). À exceção dos dados para incidência de diarréia, os demais foram submetidos à análise de regressão pelo Statistical Analysis System (SAS , 1985) e ao teste quiquadrado.

\section{Resultados e Discussão}

Os valores de nitrogênio ingerido (NING) e nitrogênio excretado pelos animais nas fezes e na urina são apresentados na Tabela 2.

Embora as quantidades de nitrogênio ingerido e de $\mathrm{N}$ excretado nas fezes tenham sido estatisticamente semelhantes ( $P>0,05)$, observou-se regressão linear significativa $(\mathrm{P}<0,01)$ para nitrogênio diário excretado na urina, ou seja, houve melhor aproveitamento dos aminoácidos dietéticos à medida que se reduziu a proteína bruta na ração até o nível de $16,5 \%$, com a suplementação de aminoácidos.

Resultados semelhantes foram obtidos por Shriver et al. (2003), ao reduzirem em quatro unidades percentuais o teor de PB na dieta de animais em crescimento. Esses autores diminuíram a quantidade de nitrogênio ingerido e observaram que, apesar de não ter ocorrido alteração no 
Tabela 2 - Nitrogênio ingerido (N ING) e nitrogênio nas fezes e na urina de leitões na fase inicial consumindo rações contendo diferentes níveis de PB

Table 2 - $\quad N$ ingested (N ING) and excreted in the feces and urine of piglets fed diets containing different dietary crude protein levels

\begin{tabular}{|c|c|c|c|c|c|}
\hline \multirow[t]{2}{*}{$\begin{array}{l}\text { Variável } \\
\text { Variable }\end{array}$} & \multicolumn{4}{|c|}{$\begin{array}{c}\text { Nível de proteína bruta (\%) } \\
\text { Crude protein level }\end{array}$} & \multirow[t]{2}{*}{ CV $(\%)^{1}$} \\
\hline & 21,0 & 19,5 & 18,0 & 16,5 & \\
\hline $\begin{array}{l}\mathrm{N} \text { ING }(\mathrm{g} / \mathrm{dia})^{2} \\
\text { Ingested } N\end{array}$ & 25,6 & 25,3 & 25,4 & 25,4 & 1,91 \\
\hline $\begin{array}{l}\mathrm{N} \text { fezes }(\mathrm{g} / \mathrm{dia})^{2} \\
N \text { feces }\end{array}$ & 3,54 & 3,48 & 4,10 & 3,60 & 21,11 \\
\hline $\begin{array}{l}\mathrm{N} \text { urina }(\mathrm{g} / \mathrm{dia})^{3} \\
N \text { urine }\end{array}$ & 4,92 & 4,42 & 3,62 & 2,89 & 15,06 \\
\hline
\end{tabular}

1 Coeficiente de variação.

2 Valores expressos com base na matéria seca.

${ }^{3}$ Regressão linear significativa $(P<0,01)$.

1 Coefficient of variation.

${ }^{2}$ Expressed in dry matter basis.

${ }^{3}$ Significant linear regression $(P<0.01)$. percentual de nitrogênio absorvido, houve maior retenção desse nutriente pelos animais que receberam rações contendo menores teores de PB. Segundo Partridge et al. (1985), a absorção de aminoácidos sintéticos é mais rápida que a dos aminoácidos presentes nas proteínas dos alimentos, uma vez que estes se encontram menos disponíveis para o animal. A maior retenção de nitrogênio nos animais que consumiram maior quantidade de aminoácidos sintéticos pode ser explicada pelo melhor equilíbrio nos sítios de síntese protéica. Em termos percentuais, o decréscimo na excreção de nitrogênio na urina foi em torno de $40 \%$, com redução de 4,5 unidades percentuais na proteína bruta da dieta, corroborando os resultados obtidos por Sutton et al. (1999). Adicionalmente, Shriver et al. (2003) sugeriram que, para cada unidade percentual reduzida no teor de proteína bruta na dieta com suplementação de aminoácidos, a excreção

Tabela 3 - Pesos relativos de fígado, pâncreas e baço de leitões aos 7, 14 e 21 dias pós-desmame, alimentados com rações contendo diferentes níveis de proteína bruta ${ }^{1}$

Table 3 - Relative weights of liver, pancreas and spleen of piglets 7, 14 and 21 days post weaning fed diets containing different dietary crude protein levels

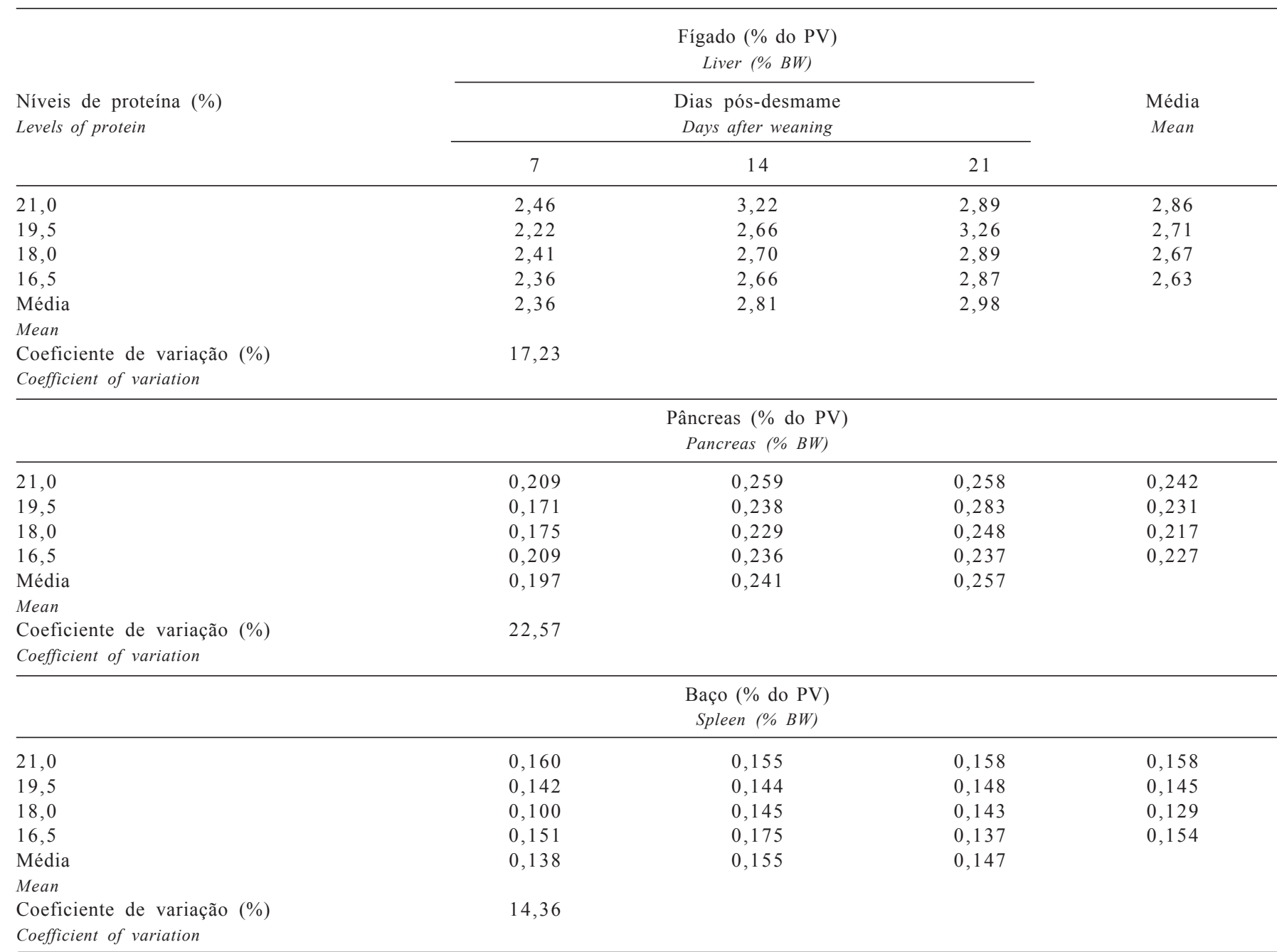

\footnotetext{
${ }^{1}$ Não houve diferenças significativas.

${ }^{1}$ Not significant differences.
} 
de nitrogênio pode ser reduzida em até $10 \%$. Neste trabalho, a excreção de nitrogênio pôde ser reduzida em até $9 \%$ nestas mesmas condições.

Os valores encontrados para os pesos do fígado, do baço e do pâncreas e para altura de vilosidades, profundidade de criptas e relação V:C encontram-se nas Tabelas 3 e 4.

Não houve diferenças significativas $(\mathrm{P}>0,05)$ para as variáveis analisadas, à exceção da profundidade de criptas na primeira semana pós-desmame, que apresentou efeito cúbico $(\mathrm{P}>0,05)$. De acordo com a literatura, esse efeito pode ser explicado pela grande variabilidade na morfometria intestinal entre os animais recém-desmamados, sendo alguns mais suceptíveis à mudança de dieta nessa fase. Nas semanas subseqüentes, a ausência de alterações indica que houve padronização entre os animais alimentados com as mesmas rações. Estes resultados confirmam os relatos de Stokes et al. (1987), citados por Silz (2000), de que os componentes alergênicos presentes na soja provocam ou não aumento da profundidade das criptas, dependendo da intensidade desses fatores. A altura de vilosidades verificada indica que a redução do farelo de soja de 32 para $22 \%$ não foi suficiente para afetar a superfície de absorção.

Os resultados dos escores de diarréia encontram-se na Tabela 5 e na Figura 1. Embora a redução do farelo de soja não tenha afetado a superfície das vilosidades intestinais, o teste qui-quadrado comprovou ser significativo $(\mathrm{P}<0,01)$ para incidência de diarréia, que foi reduzida de 8 para $1 \%$ durante a fase de creche com a redução dos níveis de PB de 21 e $16,5 \%$ respectivamente.

Tabela 4 - Altura de vilosidades, profundidade de criptas e relação vilosidade:cripta do duodeno de leitões aos 7,14 e 21 dias pósdesmame, alimentados com rações contendo diferentes níveis de proteína bruta

Table 4 - Effects of feeding different dietary crude protein levels on villous height, crypt depth and villous:crypt ratio of duodenum of pigs 7,14 and 21 days post weaning

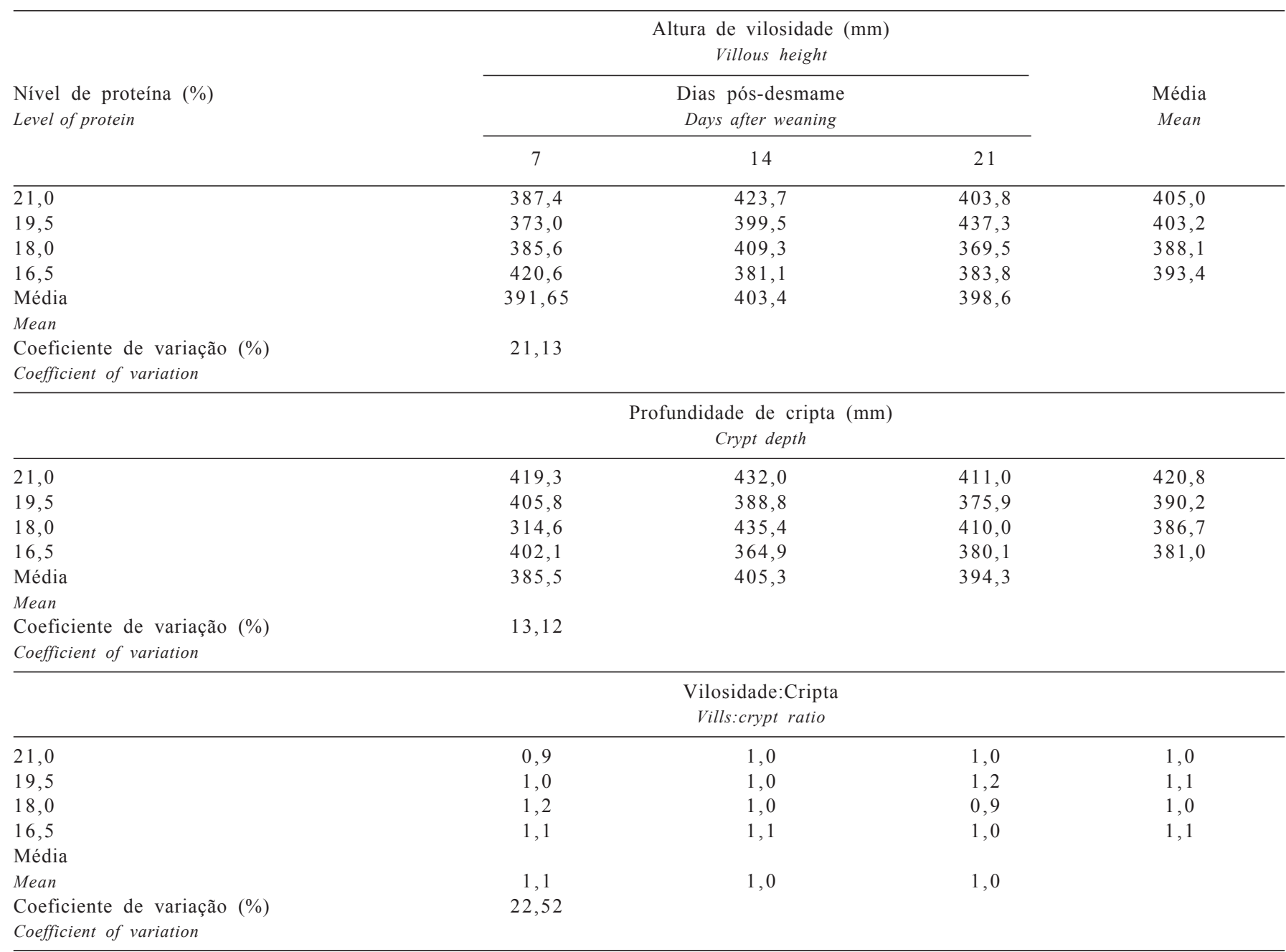

${ }^{1}$ Regressão cúbica significativa $(P<0,05)$.

1 Significant cubic regression. 
Tabela 5 - Escore fecal de leitões na fase inicial recebendo rações contendo diferentes níveis de proteína bruta Table 5 - Fecal score of piglets fed diets with different dietary crude protein levels

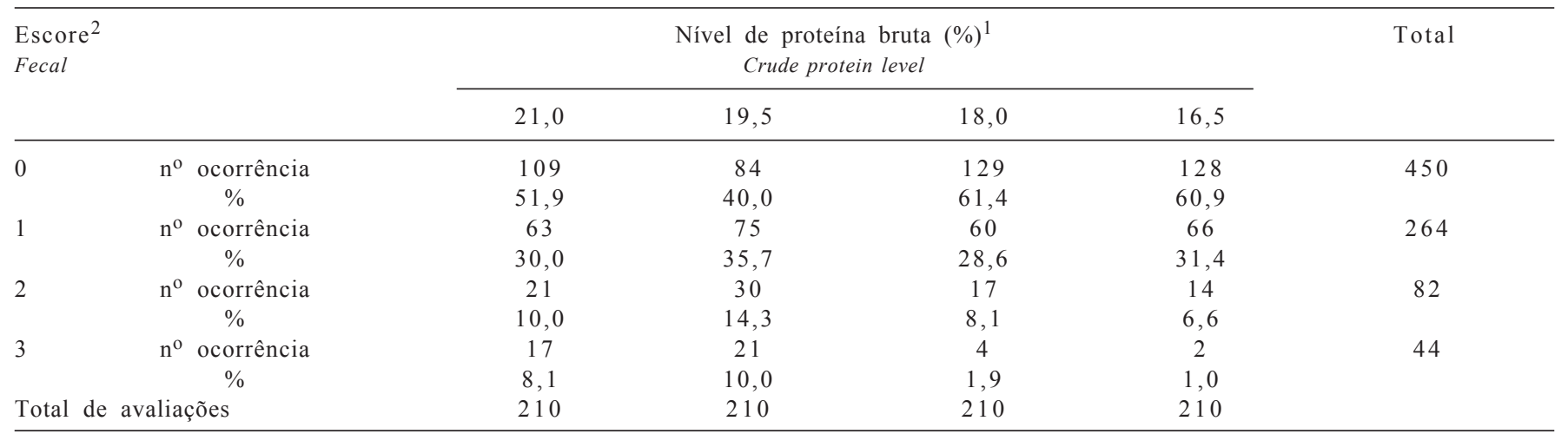

1 Significativo $(P<0,01)$ pelo teste qui-quadrado.

20 = fezes normais; 1 = fezes moles; 2 = fezes pastosas; $3=$ fezes aquosas.

1 Significant effect $(P<0.01)$ by chi square test.

$20=$ normal excrements; $1=$ soft excrements; $2=$ paste excrements; $3=$ aqueous excrements.

\section{Escore - ração com $21 \%$ PB Score - diet with $21 \% \mathrm{CP}$}

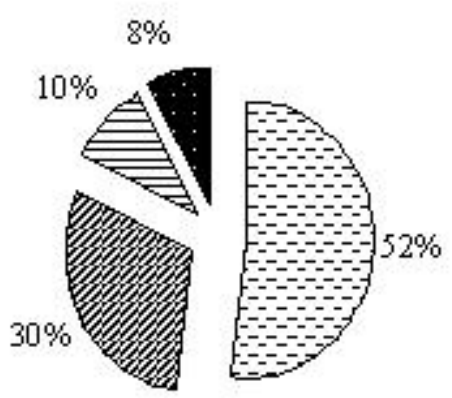

Escore - ração com 18,5\% PB Score - diet with $18.5 \% \mathrm{CP}$

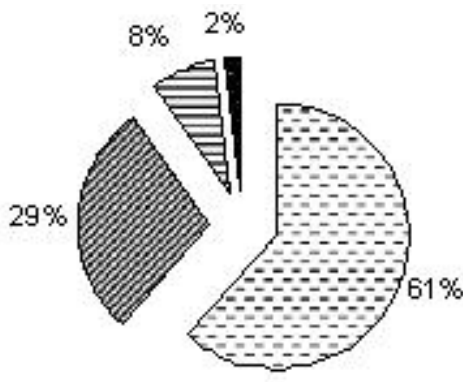

Escore - ração com $19,0 \%$ PB Score - diet with $10.9 \% \mathrm{CP}$

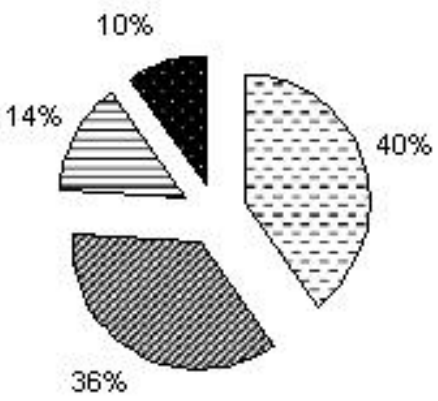

Escore - ração com $16,5 \%$ PB Score - diet with $16.5 \% \mathrm{CP}$

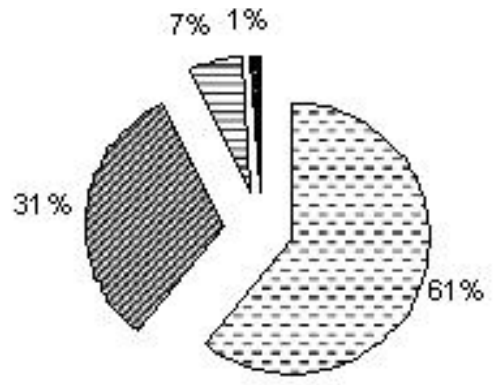

曰Nomal Mole 目 Pastosa MAquosa

Figura 1 - Escore fecal dos leitões na fase inicial recebendo rações contendo diferentes níveis de proteína bruta. Figure 1 - Effect of feeding different crude protein levels on piglet fecal score.

Valores similares para peso do fígado foram obtidos por Kerr et al. (2003), em estudo com rações contendo níveis reduzidos de PB e farelo de soja, suplementadas com aminoácidos para leitões na fase inicial. Segundo esses autores, a suplementação de dietas com aminoácidos resulta em peso do fígado equivalente ao daqueles animais que recebem rações contendo alto teor de PB. 
Tabela 6 - Ganho de peso médio diário (GPMD), consumo de ração médio diário (CRMD) e conversão alimentar (CA) de leitões, de acordo com os níveis de PB nas rações ${ }^{1}$

Table 6 - Daily weight gain (GPMD), diet intake (CRMD) and feed:gain ratio (CA) of piglets, according to crude protein levels in diets

\begin{tabular}{|c|c|c|c|}
\hline \multirow[t]{2}{*}{$\begin{array}{l}\text { Nível de proteína }(\%) \\
\text { Level of protein }\end{array}$} & \multicolumn{3}{|c|}{$\begin{array}{l}\text { Variável } \\
\text { Variable }\end{array}$} \\
\hline & $\begin{array}{l}\text { GPMD } \\
\text { (g/dia) } \\
\end{array}$ & $\begin{array}{l}\text { CRMD } \\
\text { (g/dia) } \\
\end{array}$ & $\mathrm{CA}$ \\
\hline 21,0 & 378,4 & 717,0 & 1,90 \\
\hline 19,5 & 393,0 & 773,0 & 1,97 \\
\hline 18,0 & 451,8 & 847,0 & 1,88 \\
\hline 16,5 & 420,4 & 770,0 & 1,83 \\
\hline Coeficiente de variação (\%) & 14,72 & 13,82 & 4,32 \\
\hline Coefficient of variation & & & \\
\hline
\end{tabular}

1 Não houve diferença significativa $(P>0,05)$

${ }^{1}$ No significant difference.

O mesmo se aplica ao peso do pâncreas. Segundo Jorge Neto (1992), o maior peso do pâncreas pode ser resultado da presença dos inibidores de tripsina na proteína da soja. Infere-se, portanto, que os níveis de redução propostos para o farelo de soja não foram suficientes para afetar o peso do pâncreas ou que esse ingrediente obteve adequado processamento térmico. Resultados semelhantes foram encontrados por Kerr et al. (2003), ao compararem dietas contendo 16 e $12 \%$, suplementadas com aminoácidos sintéticos (lisina, treonina e triptofano) para animais em crescimento. No entanto, observaram que o peso do pâncreas nos animais alimentados com dietas contendo $12 \%$ de PB, sem suplementação de aminoácidos, foi menor que naqueles que receberam níveis superiores deste nutriente, com ou sem a suplementação de aminoácidos.

Os valores encontrados para peso do baço sugerem que os fatores imunológicos sistêmicos não foram afetados pelos níveis de farelo de soja nas rações, confirmando as informações de Kerr et al. (2003).

Os resultados de ganho de peso médio diário (GPMD), consumo de ração médio diário (CRMD) e conversão alimentar (CA) são apresentados na Tabela 6. Não houve diferenças significativas $(\mathrm{P}>0,05)$ para as variáveis analisadas. Resultados similares foram obtidos por Ferreira et al. (2001), ao demonstrarem que a taxa de crescimento não foi influenciada pela redução em quatro unidades percentuais na PB, com suplementação de lisina, treonina e triptofano. Entretanto, redução no crescimento de suínos alimentados com rações contendo baixos teores de proteína bruta foi relatada por Hansen et al. (1993).

A redução nos teores de $\mathrm{PB}$ dietética teve pouco impacto sobre o consumo de ração, como também foi reportado por Kerr etal. (2003).
Knowles et al. (1998) observaram redução na eficiência alimentar quando diminuíram o teor de PB na dieta para quatro unidades percentuais, com suplementação de lisina, treonina, metionina, triptofano, isoleucina e valina, para animais em crescimento. Esses resultados divergem da afirmação de Suida (2001) de que, com a redução da proteína da dieta em 3 ou 4 unidades percentuais, a isoleucina, a valina e a histidina passam também a ser limitantes para manutenção do perfil ideal dos aminoácidos.

\section{Conclusões}

A redução dos níveis de proteína bruta na dieta de leitões de 21 para $16,5 \%$, com redução da participação do farelo de soja de 32 para $22 \%$ e suplementação de aminoácidos sintéticos, segundo o conceito de proteína ideal, foi eficiente para reduzir a quantidade de nitrogênio excretado na urina e não afetou o desempenho e os parâmetros fisiológicos, porém, reduziu a incidência de diarréia dos animais na fase inicial.

\section{Literatura Citada}

DE LA LLATA, M.; DRITZ, S.S.; TOKACH, M.D. et al. Effects of increasing L-lysine $\mathrm{HCl}$ in corn- or sorghum-soybean mealbased diets on growth performance and carcass characteristics of growing-finishing pigs. Journal of Animal Science, v.80, n.9, p.2420-2432, 2002.

FERREIRA, D.F. Análises estatísticas por meio do Sisvar para Windows versão 4. 0. In: REUNIÃO ANUAL DA REGIÃO BRASILEIRA DA SOCIEDADE INTERNACIONAL DE BIOMETRIA, 45., 2000, São Carlos. Anais... São Carlos: Universidade Federal de São Carlos, 2000. p.255-258.

FERREIRA, R.A.; OLIVEIRA, R.F.M.; DONZELE, J.L. et al. Redução da proteína bruta e suplementação de aminoácidos em rações para suínos machos castrados dos 15 aos $30 \mathrm{~kg}$ mantidos em estresse de calor $\left(32^{\circ} \mathrm{C}\right)$. In: REUNIÃO ANUAL DA SOCIEDADE BRASILEIRA DE ZOOTECNIA, 38., 2001, Piracicaba. Anais... Piracicaba: Escola Superior de Agricultura Luiz de Queiroz, 2001. CD-ROM.

FIALHO, E.T.; ROSTAGNO, H.S.; FONSECA, J.B. et al. Efeito do peso vivo sobre o balanço energético e protéico de rações à base de milho e de sorgos com diferentes conteúdos de tanino para suínos. Revista da Sociedade Brasileira de Zootecnia, v.8, n.3, p.386-397, 1979.

HANSEN, J.A.; KNABE, D.A.; BURGOON, K.G. Amino acid supplementation of low-protein sorghum-soybean meal diets for 5 to 20 kilogram swine. Journal of Animal Science, v.71, n.2, p.452-458, 1993.

JORGE NETO, G. Soja integral na alimentação de aves e suínos. Avicultura \& Suinocultura Industrial, v.82, n.988, p.4-15, 1992 .

JUNQUEIRA, L.C.U.; JUNQUEIRA, L.M.M.S. Técnicas básicas de citologia e histologia. São Paulo: Universidade de São Paulo, 1983. 123p.

KERR, B.J.; YEN, J.T.; NIENABER J.A. et al. Influences of dietary protein level, amino acid supplementation and environmental temperature on performance, body composition, organ weights and total heat production of growing pigs. Journal of Animal Science, v.81, n.8, p.1998-2007, 2003. 
KNOWLES, T.A.; SOUTHERN, L.L.; BIDNER, T.D. et al. Effect of dietary fiber or fat in low-crude protein, crystalline amino acid-supplemented diets for finishing pigs. Journal of Animal Science, v.76, n.11, p.2818-2832, 1998.

PARTRIDGE, I.G.; LOW, A.G.; KEAL, H.D. A note on the effect of feeding frequency on nitrogen use in growing boars given diets with varying levels of free lysine. Animal Production, v.40, n.2, p.375-377, 1985 .

ROSTAGNO, H.S.; ALBINO, L.F.T.; DONZELE, J.L. et al. Tabelas brasileiras para aves e suínos: composição de alimentos e exigências nutricionais. Viçosa, MG: Universidade Federal de Viçosa, 2000. 141p.

SALES, G.T.; FIALHO, E.T.; VOLPATO, C.T.Modificação nas gaiolas metabólicas para experimentos com suínos. In: CONGRESSO DE INICIAÇÃO CIENTÍFICA DA ESCOLA SUPERIOR DE AGRICULTURA DE LAVRAS, 26., 2003, Lavras. Anais... Lavras: Universidade Federal de Lavras, 2003. p.249.

STATISTICAL ANALYSES SYSTEM - SAS. SAS Institute user's guide: estatistics. Raleigh: 1985. p.956.

SILVA, D.J. Análise de alimentos: métodos químicos e biológicos. Viçosa, MG: Universidade Federal de Viçosa, 1990. 195p.

SILZ, L.Z.T. Fontes de proteína para leitões em fase inicial de crescimento. Jaboticabal: Universidade Estadual Paulista, 2000. 64p. Tese (Doutorado em Produção Animal) - Universidade Estadual Paulista, 2000.
SHRIVER, J.A.; CARTER, S.D.; SUTTON, A.L. et al. Effects of adding fiber sources to reduced-crude protein, amino acidsupplemented diets on nitrogen excretion, growth performance, and carcass traits of finishing pigs. Journal of Animal Science, v. 81, n.2, p.492-502, 2003

SUIDA, D. Interação da nutrição protéica com fatores econômicos, desempenho, meio ambiente e sanidade de suínos. In: SIMPÓSIO SOBRE MANEJO E NUTRIÇÃO DE AVES E SUÍNOS E TECNOLOGIA DA PRODUÇÃO DE RAÇÕES, 2001, Campinas. Anais... Campinas: Colégio Brasileiro de Nutrição Animal, 2001. p.263-284.

SUTTON, A.L.; KEPHARDT, K.B.; VERSTEGEN, M.W.A. et al. Potential for reduction of odorous compounds in swine manure through diet modification. Journal of Animal Science, v.77, n.2, p.430-439, 1999. 